\title{
Who Are Today's Grandparents?
}

Hacking Life Shifts 2020

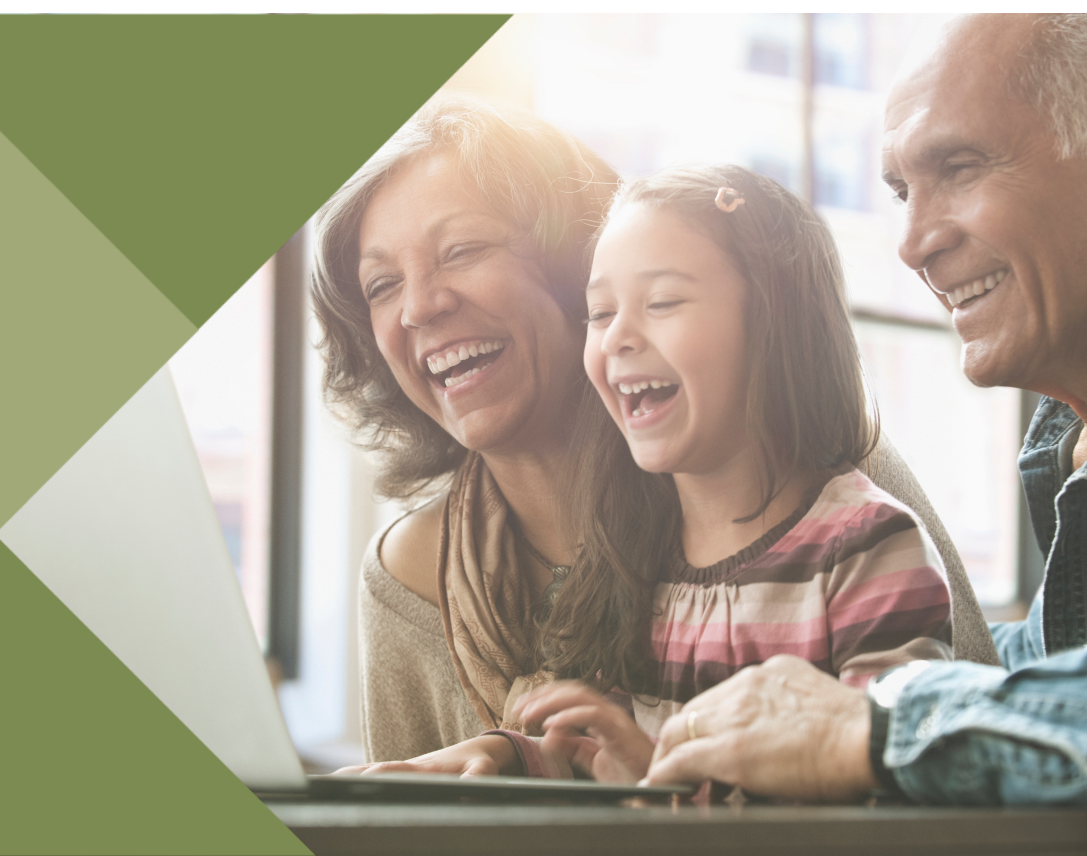

\section{Grandparents: Executive Summary}

Grandparents are in the sweet spot of life. They are positive, future focused, and see themselves as a special type of support system for their adult children and grandchildren. They are enjoying their life at this stage, comfortable with their physical, social, and emotional health. They say they're either in the best years of their life or that their best years are still ahead of them - together with their grandchildren.

\section{Grandparents: Health, Wealth \& Self}

Grandparents are also in the demographic sweet spot. Today's Grandparents are a diverse group. Many are married or living with a significant other. Married grandparents have a relatively high mean income compared to single grandparents. One third of grandparents have a multiracial or different race grandchild, ${ }^{1}$ a sign of the increased diversity of the overall population (in fact, their grandchildren will become part of the most diverse cohort in the US). Grandparents are also more likely to be working than the general 45 -plus population, which contributes to their overall sense of well-being. Adding a grandchild to the family unit creates new, fulfilling emotional connections without the full financial stress or parenting pressure.

Grandparents are happy to let their children take the parenting lead, describing it as "all the joy without all the responsibility" - when it comes to discipline. Many do struggle with the duality of their lives, typically as independent individuals still pursuing their own life's work and the idea of being someone's grandparent. While some first-time grandparents are as young as 38 , the average age of a first-time grandparent is $50 .{ }^{1}$ Many say they just don't feel old enough to be a grandparent, and some even struggle with what they want their grandchildren to call them. Mostly, though, they're excited to create memories and share life lessons with their grandchildren. 
Grandparents tend to live closer (within 20 miles) to their daughters and her children than to their sons and his kids. On average, those grandparents spend 7.5 hours a week with their grandchildren. Those who live within 20 miles spend 12.6 hours together each week. Interestingly, grandparents who live farther away are not more likely to communicate or interact virtually - via phone or text - with their grandchildren than those who live nearby.

Grandparenting is an aspirational Life Shift. While grandparents worry about things like youth and future-focused issues, such as online safety and climate change, they focus on what they want to teach or share with their grandchildren. This includes the joy of planning for and spending time together as well as the sense of purpose and bonding that occurs as a result of being a Grandparent.

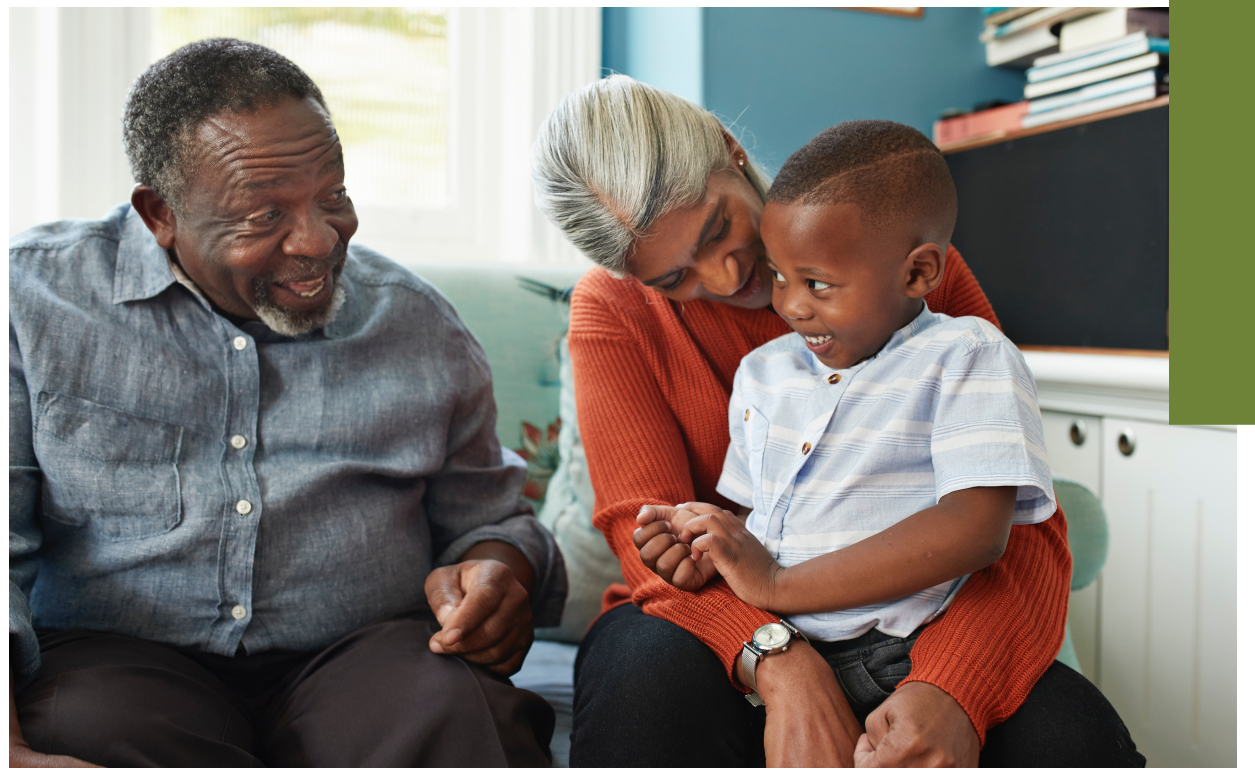

Grandparents are happy to let their children take the parenting lead, describing it as "all the joy without the all the responsibility" when it comes to discipline.

About a third of Grandparents provide some type of financial support for their grandchildren, regardless of income level and generational cohort. Those who live in closer proximity provide more financial support $-37 \%$ versus $21 \%$, with grandfathers providing more financial support than grandmothers. What do Grandparents buy for their grandkids—gifts! ${ }^{1}$ For younger grandchildren these gifts often include toys and games - in other words fun, nonessential items. More older than younger Grandparents "invest" in their grandkids' future by contributing to college funds and school tuition.

Most Grandparents report feeling no financial strain as a result of this Life Shift. Remember, for most, any financial support role they provide is voluntary, and most Grandparents are working and married, with a high mean income. They also spend on home improvement. Between $20^{1}$ - 30\% report feeling some financial strain as expectant grandparents, but this strain diminishes as grandchildren grow older. Grandparents who participated in the qualitative phase of this research described their financial participation in their grandkids' lives as contributing to college funds, purchasing life-insurance policies, and opening saving accounts for their grandchildren.

Grandparents are neither stress free nor devoid of health issues. But many are comfortable with their current health and well-being. They describe their emotional state as being positive, happy, and content, with very few offering any negative emotions about their current stage in life. Grandparents do feel a sense of urgency to get in better shape (or to stay physically fit), so they're literally able to chase after their grandkids and participate actively in their lives as long as they possibly can. 


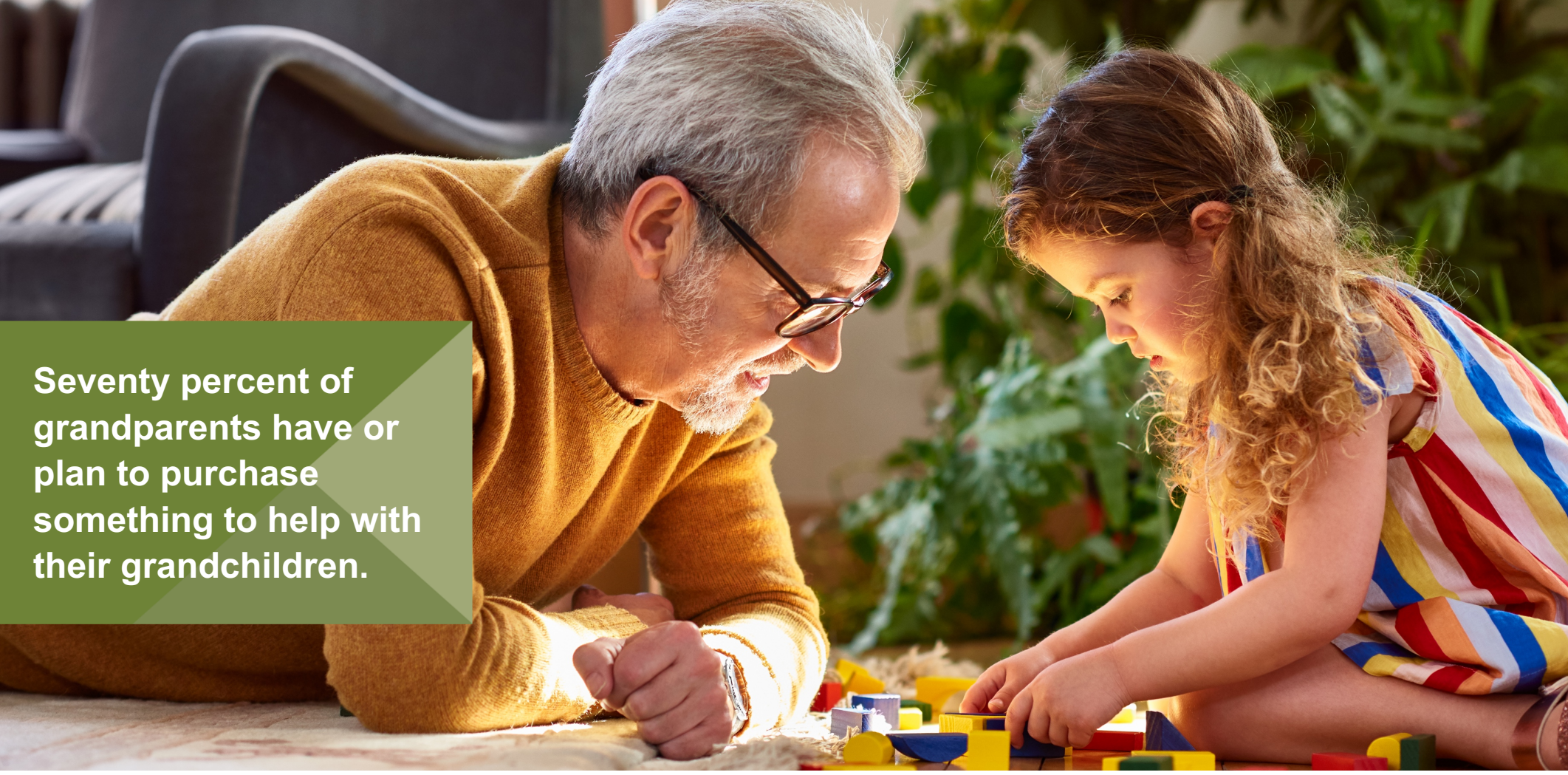

\section{Resources for Grandparents}

Most grandparents know that there are resources available to them to assist with their financial and physical health, and approximately half are aware of resources to help with emotional and social health. Less than half are aware of the availability of the same types of services for their grandchildren. Fewer actually avail themselves of these services, though about a quarter have used services relative to their personal health and financial planning.

Although over half are interested in receiving information about grandparenting, ${ }^{1}$ most grandparents do not actively seek information about being a grandparent. Twenty-five percent tend to talk with other Grandparents and check out social media. Older Grandparents cite print publications. Some participants described how they've tapped into their own parents for information and modeling. Most are seeking information about sharing experiences with grandchildren, passing on family histories, and informing their values. Grandparents also believe in financial planning for their grandchildren. Of those who do look for information, half are likely to share it with their adult children. Grandparents are active when it comes to using mobile technology, including texting, social media, and gaming.

Seventy percent of grandparents have or plan to purchase something to help with their grandchildren. Top purchases include car seats, cribs, highchairs, and clothing. Approximately a quarter of Grandparents plan to buy smart devices to help in their role. Most are buying these products in-store, but fully half are also buying online. Boomer Grandparents are shopping online at the same rate as in-store (50\%); and even more than a third (35\%) of Silents are shopping online. Walmart and Target are their top shopping locations, followed by department stores and Amazon.

Grandparenting equals joy! Nearly three-quarters of Grandparents report high rates of life fulfillment. This feeling of contentment is particularly true of those who are older and those who become Grandparents later in life. They're filled with hopes and dreams for their grandchildren and enjoy the duality of living full active lives of their own. When they do feel stress, it's focused on concerns for their own issues, not for their grandchildren. Grandparents characterize this Life Shift as the cherry on top of life's sundae. 


\section{About: The Five Life Shifts}

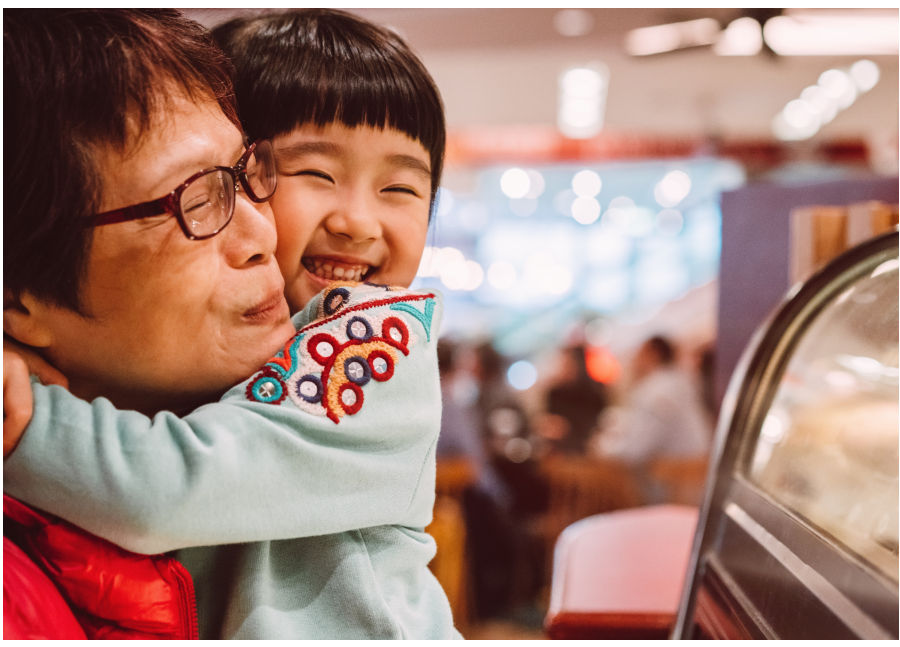

This new "Hacking Life Shifts" study dives deeply into five of the most provocative changes that can take place during the aging journey:

- Caregiving - providing ongoing informal care (usually for a spouse or parent)

- Recent Singles - moving to the next stage of life after a divorce or widowhood

- Grandparenting - becoming a grandparent

- Career Encoring - starting a new career or focusing on volunteering after ending life's work

- Changing Living Situation - relocating from one's current home to another location

None of these shifts takes place in a vacuum. Consumers frequently experience one or more at the same time. Moreover, this study focuses on recency of the shift. We recruited participants who are either immersed in the shift right now or have recently navigated through it, ensuring that the insights are fresh and the stories compelling.

\section{Methodology}

Hacking Life Shifts is a four phase research project combining secondary research, an online quantitative survey ( $n=2003$, ages 45-91), qualitative interviews and exercises, and behavioral data integration. For full methodology information, please see the Hacking Life Shifts: Methodology document. Grandparents are defined as those who are

- About to become a first time grandparent with the next 6 months or,

- Became a first time grandparent within the past 5 years.

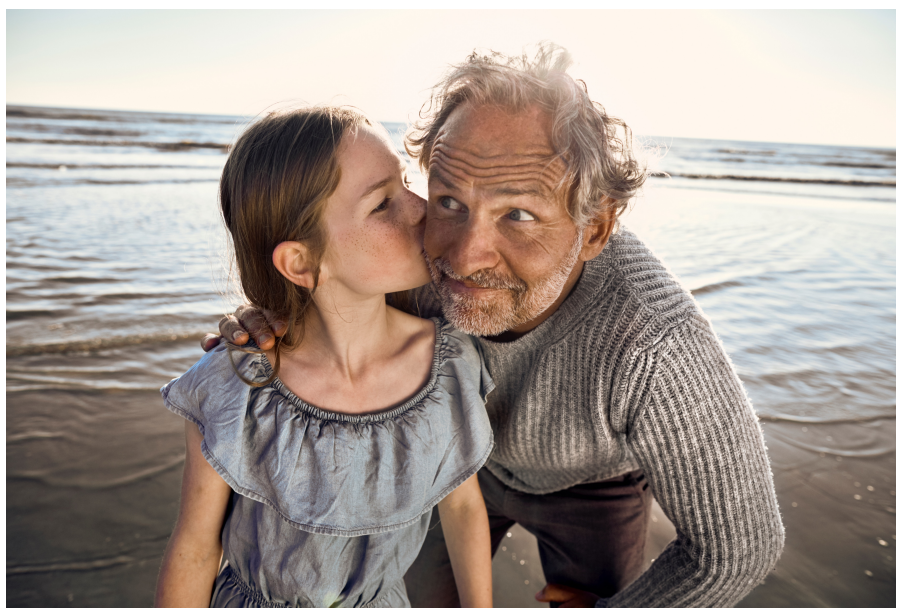

Research led by RTi Research, The Business of Aging and aha: The Strategic Online Qual Platform. Powered by Collaborata.

\begin{tabular}{l|l}
\hline & $\begin{array}{l}\text { For more information, contact Patty David, pdavid@aarp.org. } \\
\text { Real Possibilities }\end{array}$ \\
\hline
\end{tabular}

